ISSN 1997-342X (Online), ISSN 1991-8631 (Print)

Original Paper http://ajol.info/index.php/ijbcs http://indexmedicus.afro.who.int

\title{
Urinary tract candidiasis in HIV+ patients and sensitivity patterns of recovered Candida species to antifungal drugs in Dschang District Hospital (Cameroon)
}

\author{
Joel Martial DIESSE ${ }^{1}$, Frederick Agem KECHIA ${ }^{2,3}$, Yves Somo IWEWE ${ }^{2}$, \\ Aude Dougue NGUEGUIM ${ }^{1}$, Claude NANGWAT ${ }^{1}$ and Jean Paul DZOYEM ${ }^{1, *}$ \\ ${ }^{I}$ Department of Biochemistry, Faculty of Science, University of Dschang, P.O. Box 67, Dschang, Cameroon. \\ ${ }^{2}$ Medical/Clinical Mycology Laboratory, Faculty of Medicine and Biomedical Sciences, \\ University of Yaounde I, Cameroon. \\ ${ }^{3}$ Department of Biomedical Sciences, Faculty of Health Sciences, University of Bamenda, Cameroon. \\ *Corresponding author; E-mail: jpdzoyem@yahoo.fr; Tel.: +237676091031
}

\begin{abstract}
The incidence of Candida urinary tract infections is gradually on the rise and is an important public health problem. The aim of our study was to determine the prevalence of urinary tract candidiasis (candiduria) in HIV positive patients in Dschang District Hospital and the antifungal susceptibility test of isolates. A total of 285 patients were recruited for this study. Midstream urine samples were collected and processed using standard mycological techniques. Candida isolates were identified base on the colony color on CHROMagar. Antifungal susceptibility testing of the isolates was performed by the broth dilution method using four commonly used antifungals. Results showed that $22 \%$ of patients had Candida spp in their urine. Candida albicans had a proportion of $37 \%$ against $63 \%$ for non-albicans Candida. Of the 53 isolates tested, ketoconazole had the highest percentage of resistance (88.6\%) follow by fluconazole $(64.1 .6 \%)$, amphotericin B (56.6\%) and nystatin (49.0\%). The highest sensitivity was observed with nystatin (33.9\%) while the lowest was found with ketoconazole (5.6\%). In conclusion, the prevalence of candiduria among HIV positive patients in this study was $22 \%$. Candida albicans remain the most frequently involved Candida species. Azole antifungals showed the highest resistance rate against all the Candida species isolates.
\end{abstract}

(C) 2017 International Formulae Group. All rights reserved.

Keywords: HIV+ patients, Candiduria, Candida spp, Antifungal susceptibility.

\section{INTRODUCTION}

Candidiasis is a common opportunistic infection in HIV-infected patients (Kauffman, 2014). The spectrum of Candida infection is diverse, starting from asymptomatic colonization to pathogenic forms. The low absolute CD4+ T-lymphocyte count has traditionally been cited as the greatest risk factor for the development of oropharyngeal candidiasis and current guidelines suggest increased risk once CD4+ $\mathrm{T}$ lymphocyte counts fall below 200 cells $/ \mu \mathrm{L}$ 
(Anwar et al., 2012). Candiduria presents as an increasingly common nosocomial infection, which may involves urinary tract. Spectrum of disease is varying from asymptomatic candiduria to clinical sepsis. Several reports showed that the frequency of urinary tract infection due to yeasts has increased during the last decade (Yashavanth et al., 2013). Changes in the clinical severity of candidiasis and the Candida species prevalence profile may be a reflection of immunological changes in HIV positive patients. Though Candida albicans is the most frequently isolated species as a colonizer and pathogen of mucosa, other Candida species, such as $C$. tropicalis, $C . \quad$ krusei, $C$. glabrata, $C$. dubliniensis, $C$. guilliermondii, C. parapsilosis, C. kefyr, and $C$. pelliculosa, have become a significant cause of infection in patients with HIV infection (Fusi et al., 2011; Kaur et al., 2016). The clinical importance of these non-albicans Candida species lies in the fact that they are usually less susceptible to the more commonly used azole antifungal drugs, a factor that poses significant difficulties in effective treatment (Maheshwari et al., 2016). During the last few decades, the spectrum of infections has undergone a drastic change; organisms with minimal or no pathogenic role have emerged as potent pathogens and organisms once susceptible have become multidrug resistant (Ojieabu et al., 2012; Seifi et al., 2013). Emergence of non-albicans Candida species as a cause of refractory candidiasis, particularly in patients with advanced immunosuppression and problem of resistance to azoles and other antifungal agents in the Candida species is a point of concern (Lozes et al., 2012; Deorukhkar et al., 2014). Therefore, this variability in the behaviour of different Candida spp. and the increasing number of clinical isolates resistant to current antifungal therapies highlight the need for antifungal susceptibility testing to monitor the antifungal resistance of these microorganisms. The modern mycologist has an important role to play in several aspects relating to these organisms, including detection, identification, epidemiological analysis, and therapy in an attempt to better understand these pathogens and provide an effective cure (Maheshwari et al., 2016). This could guide the therapeutic choice and the clinical treatment (Terças et al., 2017). The overall prevalence of urinary candidiasis among HIV infected patients was found to be $18.8 \%$ and $36.2 \%$ in two localities of Cameroon, Buea and Yaounde respectively (Lohoué et al., 2005; Longdoh et al., 2013). However, in the west region of Cameroon, candiduria in HIV infected patients is not looking for in general practice. Yet it can be the source of disseminated infection in immunosuppressed individuals. The aim of the present study was to determine the frequency of candiduria in HIV positive patients in Dschang District hospital and to determine the susceptibility to antifungal drugs of Candida species isolated in the view to contributing to a better management of Candida infections in $\mathrm{HIV}+$ patients.

\section{MATERIALS AND METHODS}

\section{Study population}

This study was a cross-sectional study carried out during a period of 9 months, from June 2013 to February 2014 at the Dschang District Hospital. After the aim of research was clearly explained to the patients who fulfill the included criteria, patients gave written consent. The study was conducted in accordance with the declaration of Helsinki, and the protocol was approved by the Cameroon Bioethics Initiative Ethics Review and Consultancy Committee (CAMBIN 
ERRC) and an ethics clearance with reference number CBI/297/ERCC/CAMBIN was issued.

\section{Sample collection and culture}

The urine samples were collected from patients and were processed for yeasts at the laboratory of Microbiology and Antimicrobial substances of the Biochemistry Department, University of Dschang. None of the patients used antifungal during the sampling. After cleaning the genital region with a dakin solution (antiseptic), midstream urine were collected from patients into sterile urine bottles in the morning and maintained at $4{ }^{\circ} \mathrm{C}$ during transportation to the laboratory for analysis. $100 \mu 1$ of each uncentrifuged urine sample was cultured on CHROMagar Candida (CHROMagar Candida ${ }^{\circledR}$ ) containing chloramphenicol plates as lawn and incubated at $25^{\circ} \mathrm{C}$ for $48 \mathrm{~h}$. Yeasts were identified to the species level by standard methods: microscopic morphology, characteristic color displayed on CHROMagar.

\section{Antifungal susceptibility testing}

The sensitivity of obtained isolates was tested vis-a-vis of four antifungal namely: fluconazole, nystatin, amphotericin $\mathrm{B}$ and ketoconazole. The minimum inhibitory concentration (MIC) of the antifungal were determined by liquid medium microdilution technique according to the protocol described by the National Committee and Clinical Laboratory Standard (NCCLS, 2002). The interpretative breakpoints were the following: Fluconazole: Susceptible if MIC $<8 \mu \mathrm{g} / \mathrm{mL}$; Intermediary if MIC was between 16 to 32 $\mu \mathrm{g} / \mathrm{mL}$; Resistant if MIC > $64 \mu \mathrm{g} / \mathrm{mL}$. Ketoconazole: Susceptible if MIC $<0.125$ $\mu \mathrm{g} / \mathrm{mL}$; Intermediary if MIC was between 0.25 to $0.5 \mu \mathrm{g} / \mathrm{mL}$; Resistant if MIC $>1$ $\mu \mathrm{g} / \mathrm{mL}$. Amphotericin B and nystatin:
Susceptible if MIC $<1 \mu \mathrm{g} / \mathrm{mL}$; Intermediary if MIC was between 2 to $4 \mu \mathrm{g} / \mathrm{mL}$; Resistant if MIC $>4 \mu \mathrm{g} / \mathrm{mL}$ (Thérèse et al., 2006)

\section{RESULTS}

Our study population was made up of 285 patients of which 224 women $(79 \%)$ and 61 men $(21 \%)$ with a sex ratio of 3.7 in favor of the women. The average of global age of patients was $39.69 \pm 11$ years with extremes of 4 years (minimum) and 69 years (maximum). In this population, $4 \%$ (11) were children (0-20), 78\% (223) were young adults (21-49 years) and $18 \%$ (21) of more than 50 years (Table 1).

Five different Candida species were identified namely C. albicans, C. glabrata, $C$. krusei $C$. dubliniensis and $C$. tropicalis (Figure 1). The most prevalent species was $C$. albicans $37.5 \%$ followed by C. glabrata $19.4 \%$, C. krusei, $16.6 \%$, C. tropicalis $11.1 \%$ and $C$. dubliniensis $8.3 \%$. There was $6.9 \%$ of non-identified species. It is noteworthy that non-albicans Candida species emerged with $55.4 \%$ against $37.5 \%$ for Candida albicans species (Figure 1).

Among the 224 women, $21 \%$ were positive to candiduria while $6 \%$ of 64 men were positive to candiduria. Therefore, women were more affected by candiduria than men. Regarding the age groups, 21 to 49 range was the most affected $22 \%$ (48/223), follow by the $\geq 50$ age in which $19 \%$ of person were affected (4/11). About CD4+ level, $42 \%$ had 201-500 count/ $\mathrm{mm}^{3}$ followed by patients with CD4+ $\leq 200$ (31\%) (Table 2). There was an unequal distribution of the Candida species in the two sexes, with a predominance of all the species among women, except Candida dubliniensis which was predominant in men. The age range of 21-49 years was the age groups where all Candida species were the most represented, particularly Candida 
dubliniensis followed by Candida albicans and Candida glabrata. Patients with 201-500 counts $/ \mathrm{mm}^{3} \mathrm{CD} 4+$ level were the most affected by candiduria (Table 2).

The results of the antifungal susceptibility test showed a wide range of MIC value varying from $<0.125 \mu \mathrm{g} / \mathrm{mL}$ to $>256 \mu \mathrm{g} / \mathrm{mL}$ with the smallest geometric mean of $<0.54 \mu \mathrm{g} / \mathrm{mL}$. Regarding the range of inhibitory concentration and geometric mean, nystatin had the smallest range and geometric mean values for all isolates follow by amphotericin B (Table 3). All the Candida albicans species were resistant to nystatin and ketoconazole. Ketoconazole had the highest percentage of resistance towards Candida spp isolates $(88.6 \%)$, follow by fluconazole (64.1.6\%), amphotericin B (56.6\%) and nystatin $(49.0 \%)$. The highest sensitivity was observed with nystatin (33.9\%) while the lowest was found with ketoconazole $(5.6 \%)$ (Table 4).

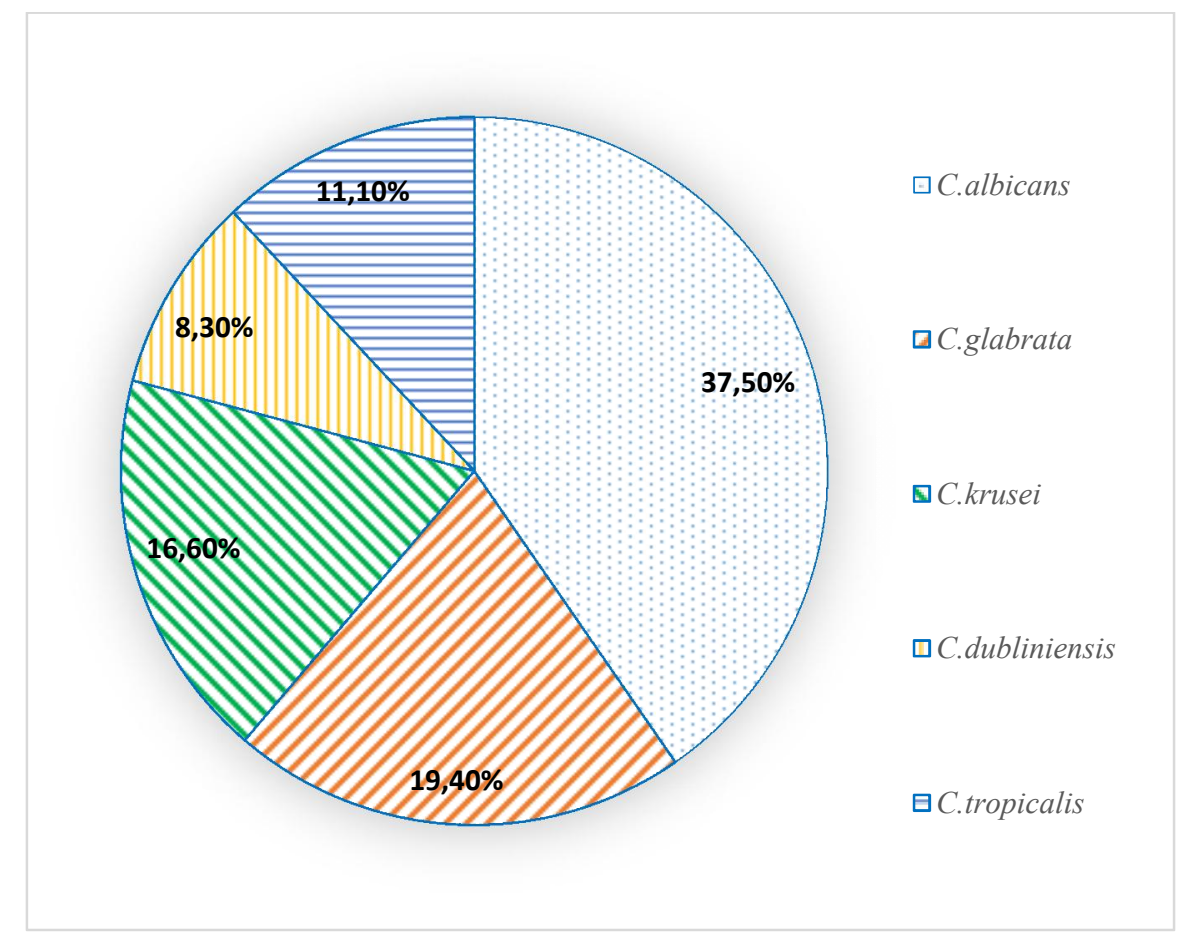

Figure 1: Distribution of identified Candida species.

Table 1: Distribution of candiduria according to sex, groups of age and CD4+ level.

\begin{tabular}{|c|c|c|c|c|c|c|c|}
\hline \multicolumn{2}{|c|}{ Sex } & \multicolumn{3}{|c|}{ Age groups (year) } & \multicolumn{3}{|c|}{ CD4+ level $\left(/ \mathrm{mm}^{3}\right)$} \\
\hline Female & Male & $\leq 20$ & $21-49$ & $\geq 50$ & $\leq 200$ & $201-500$ & $>500$ \\
\hline $47(21 \%)$ & $6(10 \%)$ & $0(0 \%)$ & $48(22 \%)$ & $4(19 \%)$ & $16(31 \%)$ & $22(42 \%)$ & $4 \quad(8 \%)$ \\
\hline
\end{tabular}


J. M. DIESSE et al. / Int. J. Biol. Chem. Sci. 11(3): 1029-1038, 2017

Table 2: Distribution of different Candida species according to sex, age groups and CD4+ level.

\begin{tabular}{|c|c|c|c|c|c|c|c|}
\hline & & $C a$ & $C g$ & $C k$ & $C t$ & $C d$ & Total \\
\hline \multirow[t]{2}{*}{ Sex } & Female & $17(96 \%)$ & $11(93 \%)$ & $10(83 \%)$ & $6(86 \%)$ & $3(83 \%)$ & $47(88.6 \%)$ \\
\hline & Male & $1(4 \%)$ & $1(7 \%)$ & $2(17 \%)$ & $1(14 \%)$ & $1(17 \%)$ & $6(11.30 \%)$ \\
\hline Age & $\leq 20$ & $0(0 \%)$ & $0(0 \%)$ & $0(0 \%)$ & $0(0 \%)$ & $0(0 \%)$ & $0(0 \%)$ \\
\hline group & $21-49$ & $16(93 \%)$ & $11(93 \%)$ & $11(92 \%)$ & $6(87 \%)$ & $4(100 \%)$ & $48(90.5 \%)$ \\
\hline (year) & $\geq 50$ & $2(7 \%)$ & $1(7 \%)$ & $1(8 \%)$ & $1(23 \%)$ & $0(0 \%)$ & $4(7.5 \%)$ \\
\hline CD4+ & $\leq 200$ & $14(77 \%)$ & $11(93 \%)$ & $10(83 \%)$ & $6(87 \%)$ & $3(83 \%)$ & $22(41.5 \%)$ \\
\hline level & $201-500$ & $3(17 \%)$ & $0(0 \%)$ & $2(17 \%)$ & $1(13 \%)$ & $1(17 \%)$ & $16(30.1 \%)$ \\
\hline$\left(/ \mathbf{m m}^{3}\right)$ & $>500$ & $1(6 \%)$ & $1(7 \%)$ & $0(0 \%)$ & $0(0 \%)$ & $(00 \%)$ & $4(7.5 \%)$ \\
\hline
\end{tabular}

Ca: Candida albicans, $\mathrm{Ck}$ : Candida krusei, Cg: Candida glabrata, Candida tropicalis, Cd: Candida dubliniensis

Table 3: Minimum inhibitory concentration (MICs) values of candida isolated to ketoconazole, Amphotericin B, fluconazole and nystatin.

\begin{tabular}{|c|c|c|c|c|c|c|}
\hline \multirow[b]{2}{*}{ Antifungals } & \multicolumn{4}{|c|}{ MIC $(\mu \mathrm{g} / \mathrm{mL})$} & \multirow[b]{2}{*}{$C t(n=7)$} & \multirow[b]{2}{*}{$C d(n=4)$} \\
\hline & & $C a(n=18)$ & $C k(n=12)$ & $C g(n=12)$ & & \\
\hline \multirow[t]{2}{*}{ Ketoconazole } & Range & $4->256$ & $<0.125->256$ & $<0.125->256$ & $2-256$ & $0.125-256$ \\
\hline & GM & 48.87 & $>5.65$ & 7.12 & 32 & 5.65 \\
\hline \multirow[t]{2}{*}{ Amphotericin B } & Range & $0.25-128$ & $2->256$ & $1->256$ & $0.25-128$ & $1-4$ \\
\hline & GM & 2.61 & 16 & $>13.92$ & 5.94 & 1.41 \\
\hline \multirow[t]{2}{*}{ Fluconazole } & Range & $8->256$ & $0.5->256$ & $1->256$ & $8->256$ & $2->256$ \\
\hline & GM & $>155.17$ & $>42.71$ & 25.39 & $>128$ & 26.90 \\
\hline \multirow[t]{2}{*}{ Nystatin } & Range & $<0.125-8$ & $0.125->256$ & $<0.125-8$ & $0.125-4$ & $1-64$ \\
\hline & GM & $<0.54$ & $>1.41$ & 1.18 & $<0.82$ & 2.82 \\
\hline
\end{tabular}

GM: Geometric mean, Ca: Candida albicans, Ck: Candida krusei, Cg: Candida glabrata, Candida tropicalis, Cd: Candida dubliniensis. $\mathrm{n}=$ number of isolate tested. 
J. M. DIESSE et al. / Int. J. Biol. Chem. Sci. 11(3): 1029-1038, 2017

Table 4: Susceptibility patterns of Candida isolates from ketoconazole, Amphotericin B, fluconazole and nystatin.

\begin{tabular}{|c|c|c|c|c|c|c|c|}
\hline Antifungals & & $C a(n=18)$ & $C k(n=12)$ & $C g(n=12)$ & $C t(n=7)$ & $C d(n=4)$ & Total \\
\hline \multirow{3}{*}{ Ketoconazole } & $\mathrm{S}$ & $0(0 \%)$ & $1(8.3 \%)$ & $1(8.3 \%)$ & $0(0 \%)$ & $1(25 \%)$ & $3(5.6 \%)$ \\
\hline & I & $0(0 \%)$ & $1(8.3 \%)$ & $2(16.7 \%)$ & $0(0 \%)$ & $0(0 \%)$ & $3(5.6 \%)$ \\
\hline & $\mathrm{R}$ & $18(100 \%)$ & $10(83.3 \%)$ & $9(75 \%)$ & $7(100 \%)$ & $3(75 \%)$ & $47(88.6 \%)$ \\
\hline \multirow[t]{4}{*}{ Amphotericin B } & $\mathrm{S}$ & $6(33.3 \%)$ & $1(8.3 \%)$ & $1(8.7 \%)$ & $3(42.9 \%)$ & $3(75 \%)$ & $14(26.4 \%)$ \\
\hline & I & $3(16.6 \%)$ & $3(25 \%)$ & $2(16.7 \%)$ & $0(0 \%)$ & $1(25 \%)$ & $9(34.6 \%)$ \\
\hline & $\mathrm{R}$ & $9(50 \%)$ & $8(66.7 \%)$ & $9(75 \%)$ & $4(57.1 \%)$ & $0(0 \%)$ & $30(56.6 \%)$ \\
\hline & $\mathrm{S}$ & $0(0 \%)$ & $2(16.7 \%)$ & $4(33.3 \%)$ & $1(14.2 \%)$ & $1(25 \%)$ & $8(15.0 \%)$ \\
\hline \multirow[t]{3}{*}{ Fluconazole } & I & $1(12.5 \%)$ & $4(33.3 \%)$ & $4(33.3 \%)$ & $0(0 \%)$ & $2(50 \%)$ & $11(20.7 \%)$ \\
\hline & $\mathrm{R}$ & $17(87.5 \%)$ & $6(50 \%)$ & $4(33.3 \%)$ & $6(85.7 \%)$ & $1(25 \%)$ & $34(64.1 \%)$ \\
\hline & $\mathrm{S}$ & $0(0 \%)$ & $8(66.7 \%)$ & $7(58.3 \%)$ & $0(0 \%)$ & $3(75 \%)$ & $18(33.9 \%)$ \\
\hline \multirow[t]{2}{*}{ Nystatin } & I & $0(0 \%)$ & $2(16.7 \%)$ & $4(33.3 \%)$ & $1(20 \%)$ & $0(0 \%)$ & $7(13.2 \%)$ \\
\hline & $\mathrm{R}$ & $18(100 \%)$ & $2(16.7 \%)$ & $1(8.3 \%)$ & $4(80 \%)$ & $1(25 \%)$ & $26(49.0 \%)$ \\
\hline
\end{tabular}

Ca: Candida albicans, $C k$ : Candida krusei, Cg: Candida glabrata, Candida tropicalis, $C d$ : Candida dubliniensis.

$\mathrm{n}=$ number of isolate tested, R: resistant, I: Intermediary, S: sensitive. 


\section{DISCUSSION}

Candida infections are the most common fungal infections in HIV patients and Candida albicans is the most involved (Guessous-Idrissi et al., 2007). However, there is more implication of non-albicans Candida in fungal infection (Fleming et al., 2002). The results of the prevalence of etiologic agents of candiduria in this study showed that nonalbicans Candida represented $55.7 \%$ against $37.5 \%$ for Candida albicans species, confirming the tendency of the general increase prevalence of non-albicans Candida in candidiasis (Abi-Said et al., 1997; Fleming et al., 2002). This study included 224 women $(79 \%)$ and 61 men (21\%) giving a sex ratio of 3.7 in favor of the women. Women are more exposed to infections than men, especially through their surface genital area and greater exposure. Esebelahie et al. (2013) previously reported the female gender as a significant risk factor for acquiring Candida infection in asymptomatic HIV patients attending a tertiary hospital in Benin City in Nigeria. In addition, the hormonal differences that exist between, the levels of estrogen and progesterone that are reduced in men could also explain this result. Indeed, Candida albicans has membrane receptors that bind progesterone colonization (Zlotnik et al., 2011). The distribution of HIV infected patients by age reported a mean overall age of $39.69 \pm 11$ years with a predominance of young adults. We also noticed a high prevalence of candiduria (92\%) among young adults. These results corroborate with those of Lohoué et al. (1991) who reported the age group of 26 to 45 as being the most affected by the candiduria. Indeed, the HIV / AIDS pandemic, as well as candiduria would be the prerogative of young sexually active populations. According to the CD4+ cell level, high prevalence of candiduria is associated with low CD4+ cell counts $(16 \%$ and $22 \%$ for $\mathrm{CD} 4+200 / \mathrm{mm}^{3}$ and between 201 and $500 / \mathrm{mm}^{3}$ respectively, compared with $4 \%$ for $>500 / \mathrm{mm}^{3}$ ). These findings are similar observation previously made by Longdoh et al. (2013) who reported that urinary candidiasis was more frequent in individuals with $\mathrm{CD} 4+\mathrm{T}$ cell count below 200 cells $/ \mu \mathrm{L}$.

Treatment against candidiasis varies substantially depending on the anatomical localization of the infection, the immune status of the patient, and the isolated species (Rex et al., 2000). In order to understand the therapeutic differences in the isolates involved in candiduria study population, we tested the sensitivity of these isolates. Our findings indicated that Candida albicans isolates were highly resistant to ketoconazole and nystatin. Among non-albicans Candida species high resistance was observed with ketoconazole against Candida tropicalis. These results can be compared with those of Sangeorzan et al. (1994) which showed failure of azoles, more particularly fluconazole in the treatment of oropharyngeal candidiasis. On the other hand, Anane et al. (2006) reported a very high sensitivity to ketoconazole from Candida albicans isolates isolated from HIV-positive recruited from a district hospital in DoualaCameroon. These results suggest the importance of antifungal susceptibility test before any prescription of antifungals; the inappropriated prescriptions could be responsible for resistant strains. It has been shown that, Candida albicans and nonalbicans Candida species differ from one to another in their epidemiology, virulence and susceptibility to antifungals, verification of 
specific implication of each species of Candida is required before any therapeutic decision (Rex et al., 2000).

\section{Conclusion}

The present study reiterates the prevalence of candiduria species among HIV positive patients in Dschang District hospital and their antifungal susceptibility pattern of Candida spp involved. The prevalence of candidiasis among HIV patients in this study was $22 \%$. Candida albicans remain the most frequently involved Candida species. Azole antifungals showed the highest resistance rate against all the Candida species isolates. Therefore, the species identification of Candida isolates along with their antifungal susceptibility pattern can help the clinicians in better treating the patients with candiduria.

\section{COMPETING INTERESTS}

The authors declare that they have no competing of interests.

\section{AUTHORS' CONTRIBUTIONS}

ISY, FAK and JPD conceived and designed the experiments; AND, JD and CN performed the experiments; ISY, CN and J.D. analyzed the data; AND and CN drafted the manuscript and JPD finalized the paper.

\section{ACKNOWLEDGEMENTS}

JPD is thankful to "The World Academy of Sciences (TWAS) for the advancement of science in developing countries" and to Committee on Scientific and Technological Cooperation (COMSTECH) for the (COMSTECH)-TWAS Joint Research Grants Programme awarded to provide equipment used for this work.

\section{REFERENCES}

Abi-Said D, Anaissie E, Uzun O, Raad I, Pinzcowski H, Vartivarian S. 1997. The epidemiology of hematogenous candidiasis caused by different Candida species. Clin. Infect. Dis., 24(6): 11221128. DOI: http://www.jstor.org/ stable/4460015.

Anane S, Khalfallah F. 2006. Diagnostic biologique des candidoses systémiques: difficultés et perspectives. Pathol. Biol., 55(5): 262-272. DOI: 10.1016/j.patbio.2006.03.003.

Anwar KP, Malik A, Subhan KH. 2012. Profile of candidiasis in HIV infected patients. Iran J. Microbiol., 4(4): 204-209. DOI: http://ijm.tums.ac.ir/index.php/ ijm/article/view/669/0.

Deorukhkar SC, Saini S, Mathew S. 2014. Non-albicans Candida Infection: An emerging threat. Interdiscip. Perspect. Infect. Dis., 2014: 615958. DOI: 10.1155/2014/615958.

Esebelahie NO1, Enweani IB, Omoregie R. 2013. Candida colonisation in asymptomatic HIV patients attending a tertiary hospital in Benin City, Nigeria. Libyan J. Med., 8: 20322. DOI: 10.3402/ljm.v8i0.20322.

Fleming RV, Walsh TJ, Anaissie EJ. 2002. Emerging and less common fungal pathogens. Infect Dis Clin North Am., 16 (4): 915-933. DOI: http://dx.doi.org/10.1016/S0891-5520 (02)00041-7.

Fusi NCNK, Payne VK, Asakizi AN. 2012. Non-classical reproductive tract infections on the rise in women in Dschang, Cameroon. Int. J. Biol. Chem. Sci., 6(5): 2016-2025.

DOI: http://dx.doi.org/10.4314/ijbcs.v6i5.11 
Guessous-Idrissi N, Essari A, Abdallaoui S, Youssouf M. 2007. Première identification de Candida dubliniensis au centre hospitalier universitaire Ibn Rochd de Casablanca, Maroc. J Mycol Med., 17 (2): 77-81.

DOI:

10.1016/j.mycmed.2007.03.003.

Kauffman CA. 2014. Diagnosis and management of fungal urinary tract infection. Infect. Dis. Clin. North. Am., 28(1): 61-74. DOI: $10.1016 /$ j.idc.2013.09.004.

Kaur R, Dhakad MS, Goyal R, Kumar R. 2016. Emergence of non-albicans Candida species and antifungal resistance in intensive care unit patients. Indian. $J$. Microbiol. Res., 3(4): 398-400. DOI: https://doi.org/10.1016/j.apjtb.2015.12.019

Lohoué J, Nomo O A, Same E A. (1991). Candidose et SIDA à Yaoundé. Bull Soc Pathol Exot., 84(2): 133-135.

Lohoué JP, Angwafo III FF, Kechia FA, Noukeu ND. 2005. Candiduria in HIV Infected Patients in Yaoundé, Cameroon. Afr. J. Urol., 11(1): 61-65.

Longdoh A. Njunda, Jules C. N. Assob, Shey D. Nsagha, Henri L. F. Kamga, Ejong C. Ndellejong, Tebit E. Kwenti. 2013. Oral and urinary colonisation of Candida species in HIV/AIDS patients in Cameroon. Basic Sci. Med., 2(1):1-8. DOI: 10.5923/j.medicine.20130201.01.

Lozes E, Ahoussinou C, Agassounon M, TchibozoDjikpo, Dahouegnon E, Ahossouhe N, Acoty A, De Souza C. 2012. Variabilité du taux des lymphocytes CD4 et de la charge virale chez les personnes vivant avec le VIH sous thérapie antirétrovirale : cas de l'hôpital saint jean De Dieu de Tanguieta (Benin). Int. J. Biol. Chem. Sci., 6(2): 650-656.
DOI:

http://dx.doi.org/10.4314/ijbcs.v6i2.9.

Maheshwari M, Kaur R, Chadha S. 2016. Candida species prevalence profile in HIV seropositive patients from a major tertiary care hospital in New Delhi, India. $J$ Pathog., 2016: $6204804 . \quad$ DOI: $10.1155 / 2016 / 6204804$.

National Commitee for Clinical Laboratory Standards (NCCLS). 2002. Reference method for broth dilution antifungal susceptibility testing of yeasts. Approved standard (NCCLS document M27-A2) Villanova, PA: National Committee for Clinical Laboratory Standards.

Ojieabu WA, Femi-Oyewo MN, Ojieabu CI. 2012. Impact of educational status on HIV/AIDS knowledge, attitude and misconception among pregnant women. Int. J. Biol. Chem. Sci., 6(4): 1582-1592. DOI: http://dx.doi.org/10.4314/ ijbcs.v6i4.18.

Rex JH, Walsh TJ, Sobel JD, Filler SG, Pappas PG, Dismukes WE, Edwards JE. 2000. Practice guidelines for the treatment of candidiasis. Clin. Infect. Dis., 30 (4): 662-678. DOI: 10.1086/313749.

Sangeorzan JA, Bradley SF, He X, Zarins L T, Ridenour GL, Tiballi RN, Kauffman CA. 1994. Epidemiology of oral candidiasis in HIV-infected patients: colonization, infection, treatment, and emergence of fluconazole resistance. $\mathrm{Am} \mathrm{J}$ Med., 97(4): 339-346. DOI: 10.1016/00029343(94)90300-X.

Seifi Z, Azish M, Salehi Z, Mahmoudabadi AZ, Shamsizadeh A. 2013. Candiduria in children and susceptibility patterns of recovered Candida species to antifungal drugs in Ahvaz. J. Nephropathology, 2(2): 122-128. DOI:10.12860/JNP.2013.20. 
Terças AL, Marques SG, Moffa EB, Alves MB, de Azevedo CM, Siqueira WL, Monteiro CA. 2017. Antifungal Drug Susceptibility of Candida Species Isolated from HIV-Positive Patients Recruited at a Public Hospital in São Luís, Maranhão, Brazil. Front. Microbiol., 8: 298. DOI: 10.3389/fmicb.2017.00298.

Thérèse L., Bagyalakshmi R., Madhavan N., Deepa P. 2006. In vitro suscepbility testing by agar dillution method to determine the minimum inhibitory concentrations of amphotericin B, fluconazole and ketoconazole agains ocular fungal isolates. Indian J. Med. Microbiol., 24(4): 273-279. DOI: 10.4103/0255-0857.29386.
Yashavanth R, Shiju MP, Bhaskar UA, Ronald R, Anita KB. 2013. Candiduria: prevalence and trends in antifungal susceptibility in a tertiary care hospital of mangalore. J. Clin. Diagn. Res., 7(11): 2459-2461.

DOI: 10.7860/JCDR/2013/6298.3578.

Zlotnik A, Ohayon S, Gruenbaum BF, Gruenbaum SE, Mohar B, Boyko M, Klin Y, Sheiner E, Shaked G, Shapira Y, Teichberg. 2011. Determination of factors affecting glutamate concentrations in the whole blood of healthy human volunteers. $J$ Neurosurg Anesthesiol., 23(1): 45-49. DOI: 10.1097/ANA.0b013e3181f82a8f. 